P. Henríquez P., J. P. Amaya G., C. Díaz C., C. Contreras B., L. Flores. Dramaturgias de la memoria del teatro contemporáneo de Concepción

\title{
DRAMATURGIAS DE LA MEMORIA DEL TEATRO CONTEMPORÁNEO DE CONCEPCIÓN
}

\section{DRAMATURGIES MEMORY OF CONTEMPORARY THEATER OF CONCEPCIÓN*}

\author{
Patricia Henríquez Puentes \\ Juan Pablo Amaya González \\ Carolina Díaz Castro \\ Camila Contreras Benavides \\ Lilian Flores \\ Universidad de Concepción, Chile \\ pathenriquez@udec.cl
}

\section{Resumen:}

Este artículo revisa las modalidades a través de las cuales el teatro contemporáneo de Concepción construye dramaturgias textuales y escénicas que actualizan antiguas relaciones entre teatro y memoria, en un juego de cuestionamientos, recolecciones, disputas, sobreexposición y valorización testimonial. Se ejemplifica con dos de las compañías teatrales representativas de las artes escénico teatrales de la ciudad, La Otra Zapatilla y Teatro Uno.

Palabras clave: teatro - memoria - Concepción - testimonio - política-investigación

\begin{abstract}
:
East article checks the modalities across which the contemporary theatre of Concepcion constructs textual and scenic dramaturgies that update former relations between theatre and memory, in a game of questions, compilations, disputes, overexposure and nominal valuation. One is exemplified by two of the theatrical representative companies of the arts scenic theatrical of the city, La Otra Zapatilla and Teatro Uno.
\end{abstract}

Keywords: theatre - memory - Concepción - testimony - politics - investigation

Recibido: 12/5/ 2017

Aceptado: 30/6/2017

\footnotetext{
* Esta investigación forma parte del Proyecto Fondart Investigación N7461, 2013, "Procesos creativos del teatro contemporáneo de Concepción: espacio y memoria". Consejo Regional de la Cultura y las Artes. Región del Bío Bío. Investigador responsable: Dra. Patricia Henríquez P. Coinvestigadores: Dr. Juan Pablo Amaya, Mag Lilian Flores. Colaboradores: Dra. Carolina Díaz, Dra. Camila Contreras. Grupo de Investigación Lenguajes Escénicos Teatro. Dirección de Investigación de la Universidad de Concepción y Programas de Postgrado en Literatura de la Universidad de Concepción. Autor para correspondencia: Dra.Patricia Henríquez Puentes*. Dirección completa: Departamento de Español. Facultad de Humanidades y Arte. Universidad de Concepción. Barrio Universitario s/n Concepción. Teléfono: 0412203001 / 0412204313 Correo electrónico: pathenriquez@udec.cl
} 
En el año 2003, la Dra. Marta Contreras afirmaba en el inicio del libro Historias del teatro de la Universidad de Concepción que "Las ciudades contienen muchas ciudades, entre ellas, la ciudad teatral con su música propia se entrama con otras creando espacios donde algunas de ellas se pueden tocar: En torno al TUC se articuló la ciudad teatral de Concepción por varias décadas" (9). Con el término del Teatro de la Universidad de Concepción el año 1973, la ciudad quedó huérfana de un teatro que la habitara. Desde Santa Juana de América, la última obra de la compañía universitaria, hasta nuestros días, Concepción ha sido una ciudad sin teatro institucionalizado, pues las escuelas de teatro surgidas en planteles privados cerraron tras las primeras generaciones egresadas, los nuevos actores titulados formaron compañías que ponen en escena montajes esporádicos, sin regularidad temporal.

Sin embargo, son esos actores y sus compañías, pese a todas las dificultades, quienes construyen una ciudad teatral particular y visualizan el compromiso que su teatro establece con Concepción. Sus montajes, con dramaturgia individual y colectiva, llevan a los “escenarios teatrales, síntesis lúdicas, aglutinan en su interior, cristalizan diamantinamente escenas de pasión, de pensamiento, de acción que nos retratan en nuestra confusa condición humana, en nuestra diversidad irrepetible o en nuestros más profundos temores y deseos" (26). Es por ello que interesa estudiar el teatro contemporáneo de Concepción, en la medida que es un teatro que se pregunta por sus posibilidades en torno a la memoria, a la ciudad, al país, a través de una diversidad de propuestas escénicas en las que convive el drama tradicional, en el que predomina la hegemonía de la fábula, la mímesis y la representación, con otro, en que estos conceptos claves comienzan a desedibujarse para dar paso a la narrativización, a la exposición de acontecimientos y en general, a una polifonía de materiales y voces propios de las llamadas "dramaturgias de lo real” (Sánchez 16).

\section{Memoria, olvido y recuerdo}

La memoria, a la que los griegos concibieron en su mitología como la madre de todas las artes y las ciencias, incluida también la propia historia, es entendida por Ricoeur como ese vínculo original de la conciencia con el pasado. La memoria es el presente del pasado, cumple así la tarea de restituir lo que ha tenido lugar, por lo cual se halla en su seno la huella del tiempo (13). Esa continuidad entre el pasado y el presente permite que nos 
P. Henríquez P., J. P. Amaya G., C. Díaz C., C. Contreras B., L. Flores. Dramaturgias de la memoria del teatro contemporáneo de Concepción

remontemos sin solución de continuidad desde el presente vivido hasta los acontecimientos más lejanos de nuestra infancia (3). La memoria, desde este punto de vista, vendría a ser la capacidad para recorrer y remontar el tiempo en búsqueda de ciertos recuerdos que, en palabras de Ricoeur, se distribuyen y organizan en niveles de sentido o en archipiélagos separados posiblemente mediante precipicios. La memoria, señala Steiner, es el don humano que hace posible todo aprendizaje, el entendimiento y la anticipación equivalen a un acto de remembranza (128-129). Según ello, la memoria protege el aprendizaje a través de la conservación de las impresiones del pasado y de la lucha contra el olvido (Ricoeur 8).

La amenaza de la memoria es esa facultad inhibitoria activa implicada en el olvido (Nietzsche 31), verdadero mecanismo de autoprotección que tiende a eliminar o disminuir espontáneamente las experiencias negativas para conservar y destacar las positivas. Ricoeur señala que una memoria sin olvido sería insoportable (9). Y añade que el olvido es la estrategia necesaria para la instrumentación de la memoria, permitiendo la selección de ciertos recuerdos, de ahí que la memoria posea un significado positivo en la medida en que el “carácter de sido" prevalece sobre el "ya no" en el significado vinculado a la idea de pasado (8). Lo propio señala Todorov cuando concluye que la memoria no se opone absolutamente al olvido, sino que marca la interacción entre la supresión (olvido) y la conservación (3). Casi podría decirse que la memoria, lejos de oponerse, es el olvido.

\section{Teatro y memoria}

El teatro, al igual que la performance, entendida como "conducta restaurada" (Schechner 13) o "proceso reiterativo y de traspaso" de saber social, memoria y sentido de identidad (Taylor 1) es depósito de memoria cultural y colectiva, en este sentido, está sujeto a continuos ajustes y modificaciones (Carlson 12), a ensamblajes de materiales diversos, entre los cuales están los materiales de obras anteriores.

sabemos que hay un texto no constituido por una fila de palabras, de las que se desprende un único sentido, teológico, en cierto modo (pues sería el mensaje de un Autor-Dios), sino por el espacio de múltiples dimensiones en el que se concuerdan y contrastan diversas escrituras, ninguna de las cuales es la original: el texto es un tejido de citas provenientes de los mil focos de una cultura (Barthes 69). 
Si la memoria es el presente del pasado, el teatro en tanto depósito de la memoria cultural, es el lugar en el que el pasado se hace presente en todo su esplendor tridimensional, es el espacio en el que ese tejido de citas provenientes de los mil focos de la cultura -en palabras de Barthes- cobran vida frente a nuestros ojos en una "una tapicería de fantasmas" (Carlson 149), que remueven en diversos grados nuestros recuerdos individuales $\mathrm{y}$ colectivos. La relevancia del teatro como depósito de la memoria radica en su potencialidad para restaurar esa gramática orgánica del pasado que no cabe dentro de las palabras (Spregeldburd 4), para restablecer lo que calla el discurso y no ha podido ordenarse bajo el sentido verbal (Cornago 24), lo que excede y desborda la palabra oral y escrita y sólo se hace visible como recurso corporal configurador de significados.

Toda recepción está atravesada por la memoria, la que provee los códigos y estrategias que modelan la recepción. Al cambiar las memorias culturales y sociales, se modifican también los parámetros en el marco de los cuales funciona la recepción, parámetros que el teórico Hans Robert Jauss llama "horizonte de expectativas". Las expectativas que los espectadores o lectores tienen ante una nueva experiencia teatral son equivalentes a los residuos de las experiencias anteriores semejantes. Este proceso ocurre en cualquier actividad que implique interpretar (14).

\section{Testimonio y memoria}

El testimonio, en tanto "cuerpo discursivo que afecta y es afectado" (Rodríguez 113), determina la construcción de la historia de un grupo y/o de una nación. De ahí que el testimonio individual, el que expresa una persona que en relación a un tercero da a conocer algo, esté relacionado dialécticamente con el universo en que se halla, según una relación, entre individuo y sociedad, que puede ir desde la armonía hasta la negación.

La palabra testimonio "deriva desde el latín de dos expresiones: testa y superstos. En la primera acepción se indica que el testimonio es la persona que atesta, es decir, que da testimonio, es una persona que en relación a un tercero da a conocer algo, que actúa como una experiencia y tiene que ver con una experiencia vivida, algo ocurrido a modo de recuerdo, dando a entender que ese testigo estuvo ahí. En la segunda definición, ese testigo se identifica con la expresión superviviente, el que sobrevivió y por este hecho es capaz de dar testimonio de algo (Agamben 9). 
P. Henríquez P., J. P. Amaya G., C. Díaz C., C. Contreras B., L. Flores. Dramaturgias de la memoria del teatro contemporáneo de Concepción

Memoria y testimonio manifiesta su estrecha relación, especialmente cuando consideramos al testigo como un sobreviviente, es decir, como alguien que ha vivido una experiencia absolutamente inolvidable y que en el relato que realiza respecto de ella permite que los otros, los que leen o escuchan, se aproximen al "inconsciente de la experiencia" (Didi Huberman 34). Es importante recordar que la experiencia de un sobreviviente es siempre una "verdad inimaginable es decir, irreductible a los elementos reales que la constituyen", tal como lo señala Agamben (5). El superviviente o testigo, representante de una minoría anómala y exigua, tiene la vocación de la memoria, no puede no recordar (14), debido justamente al privilegio de la supervivencia que pone en tela de juicio su identidad y credibilidad, en tanto los verdaderos testigos son los que "han tocado fondo", los sobrevivientes vienen a ser unos seudotestigos que hablan en su lugar, por delegación (1718).

\section{Teatro, memoria y política}

El teatro contemporáneo, en palabras de Dubatti, "instala un campo de verdades subjetivas y diversas" (115). Habría que agregar que estas verdades se presentan en la escena teatral intensificadas por los lenguajes de lo simbólico y lo poético, la mayoría de las veces con la clara intención de invitarnos a repensar, reimaginar y reconfigurar lo propio a través de la visibilización de sus fisuras, vacíos y carencias (Mansilla 2); y con ello, a ratificar y/o cuestionar la macropolítica del statu quo y/o los imaginarios colectivos más extendidos y arraigados (Dubatti 115). En otros casos, estas verdades conciernen a lo escénico teatral y a hacer visible la progresiva renuncia a la mímesis y a la representación del teatro contemporáneo.

Ranciere afirma que la literatura hace política en tanto literatura (15). Con esto viene a descartar que la literatura haga política según el compromiso partidista o revolucionario de los escritores que la producen, como había sido entendida por la poética social vinculada a una literatura comprometida de la izquierda de principios del siglo $\mathrm{XX}$.

Entonces, si la política de la literatura no es la política de los escritores, alude al rol que tienen las artes en general en la conformación de los imaginarios sociales. Para el caso de la literatura, ésta participa en la política porque es capaz de poner en común ciertos 
imaginarios o silenciar otros, aquello que el autor llama "participación en el reparto de lo sensible": "esta distribución y esa redistribución de los espacios y los tiempos, de los lugares y las identidades, de la palabra y el ruido, de lo invisible" (16).

De forma más clara, cuando la literatura "pone en escena lo común de los objetos y de los sujetos nuevos. Hace visible lo que era invisible, hace audibles cual seres parlantes a aquellos que no eran oídos sino como animales ruidosos" (17), gracias a las palabras utilizadas y que vehiculan la comunicación.

Si bien Rancière se refiere a la literatura, es posible ampliar sus palabras como sinécdoque para el teatro pues éste en su doble conformación, es literatura más textualidad escénica. Por lo tanto, el teatro es más político aún en virtud de que también, al igual que la literatura, interviene "en el recorte de los objetos que forman un mundo común, de los sujetos que lo pueblan, y de los poderes que éstos tienen de verlo, de nombrarlo y de actuar sobre él” (20-21) y es capaz de escenificarlos frente a públicos diversos en ese momento de comunión del hic et nunc de la representación teatral.

Como reconoce Rancière, ha existido en el teatro, la tendencia equivocada a considerar al espectador como un ser pasivo que se limita a recibir y a reaccionar frente a lo que el dramaturgo, actores, directores y técnicos han presupuestado como su comportamiento. En un trabajo anterior titulado El maestro ignorante (2011), Rancière recoge el pensamiento de Joseph Jacotot, de principios del siglo diecinueve, quien afirmaba que era posible que un ignorante enseñara a otro aquello que él mismo no sabía.

El maestro ignorante sirve como ejemplo para comprender que el teatro aspira a la igualdad puesto que se supera el modelo tradicional de un espectador pasivo, al emanciparlo: esto es, comprender que es activo pues "observa, selecciona, compara, interpreta. Conecta lo que observa con otras cosas que ha observado en otros escenarios, en otros tipos de espacios" (9). Pensar así la relación entre actores y espectadores es apostar por la igualdad, en tanto que el "espectador es actor en su propia historia y que todo actor es a su vez el espectador del mismo tipo de historia" (12).

La utilidad de considerar el teatro como lo hace Rancière es que "nos puede servir para entender mejor cómo palabras, historias y performances pueden ayudarnos a cambiar algo en el mundo en el que vivimos" (16) pues sabemos que tanto actores como espectadores 
P. Henríquez P., J. P. Amaya G., C. Díaz C., C. Contreras B., L. Flores. Dramaturgias de la memoria del teatro contemporáneo de Concepción

son creadores e intervienen en ese reparto de lo sensible. En síntesis, ambos hacen la política, es posible agregar, del teatro.

\section{Memoria, política y testimonio en el teatro de Concepción}

Este estudio revisa las modalidades de la memoria en dos elencos teatrales contemporáneos de la ciudad de Concepción: Compañía La otra zapatilla y Compañía Teatro Uno. Interesa focalizar en tres de sus propuestas: A lo mejor ahora está lloviendo (2012) y Víctor, un canto para alcanzar las estrellas (2013) de La otra zapatilla y Niño perro de Teatro Uno (2011).

\subsection{Compañía La otra zapatilla}

La Compañía teatral La otra zapatilla ${ }^{1}$ fundada el año 2007 en Concepción, se ha caracterizado por una propuesta teatral en la que suele convivir una diversidad de materiales y textualidades, lo que además de poner en tensión el principio de representación, genera una polifonía escénica que invita-obliga al espectador a desarrollar formas diversas de interpretación. Es precisamente desde la escena que esta Compañía va al "encuentro del texto" (Danan 23, 25). Este, por lo tanto, no se constituye en fundamento de la escena, sino más bien es uno más de los elementos de la polifonía del espectáculo (33).

A lo mejor ahora está lloviendo es una de las obras más escenificadas de este elenco, probablemente porque es una de sus propuestas en las que se hace evidente con mayor claridad una poética que, entre otras cosas, desplaza la mímesis para enfatizar la narrativizacion e instalar la discontinuidad y la distancia. La obra se inicia con dos actrices y un actor que "se preparan para un ensayo. Hacen training y caminan por el escenario" (La

\footnotetext{
${ }^{1}$ La otra zapatilla fue fundada en Concepción el año 2007, reuniendo entre sus integrantes a actores y actrices egresados de la Escuela de Teatro de la Universidad del Desarrollo de la ciudad. Entre sus obras destacan: Memorias de la Concepción, Louta, El Ganso, A lo mejor ahora está lloviendo, Te-evito, Víctor, un canto para alcanzar las estrellas, Amores de Mercado, El Principito, El Ganso, La comedia del Mercado, La Final, Ana Frank, Geografía del mito y la leyenda, El día en que la tierra se enfermó, Robertita, báñate, El día de Susanita, El viaje de Pablito, Sarita desorden, Rojoberto y Don Quijote de la Mancha, Robertita y Pajaritos en la cabeza, Mi fiesta patria y Titiloco. Concepción, Chile: Compañía La Otra Zapatilla, 2007.
} 
otra zapatilla 3), mientras relatan fragmentos de su vida, en búsqueda de un motivo para construir una fábula, la que, por lo demás, no deja de ser un proyecto hasta el final de la obra. Es más, en ningún momento las actrices y el actor "viven una acción a los ojos del espectador" (Viviescas 441). Por lo tanto, tampoco se expresan a través de los diálogos en nombre de un personaje determinado, ni narran al público espectador, sino que "se narran entre sí". Durante el montaje, nunca dejan de ser Óscar Cifuentes, Maira Perales y Daniela Ortiz, integrantes del elenco La otra zapatilla. La obra explora, en este sentido, en las fronteras entre la ficción y la realidad, la representación y la presentación, la mímesis y la narración, lo dramático y lo épico. De ahí que pueda ser considerada una propuesta representativa de un teatro que "explora en una teatralidad fronteriza" (García Barrientos 521).

En palabras de Carolina Henríquez, Directora del montaje "los asuntos presentados en esta obra tienen que ver también con los problemas que mueven a nivel autobiográfico al elenco". De ahí que se pueda afirmar que en esta propuesta es evidente una dialéctica de la memoria individual y colectiva en el marco de las microhistorias locales, en este caso, de las historias vinculadas a sectores aledaños a la comuna de Concepción: Boca Sur, Agüita de la Perdiz, Laguna de los Negros, Chiguayante, Coronel, Cañete y Quilantahue en Tirúa. En este sentido, el énfasis en esta propuesta no está puesto en la fábula y en la representación, sino en el entramado de materiales dispares y cuidadosamente expuestos en el aquí y ahora de la escenificación para, presentar un asunto que es también el asunto del teatro del siglo XXI.

A lo mejor ahora está lloviendo habla sobre el destierro experimentado por aquellos que han sido expulsados de sus referentes y entornos de sentimientos y pensamientos de arraigo y pertenencia; y en general, sobre los que han vivido una "ausencia a pedazos", tal como lo señala Mario Benedetti en el poema La Patria, citado textualmente en la obra. Entre éstos están los mapuches, los pobladores, los exiliados e incluso, los desterrados de sus hogares después del terremoto que asoló Concepción y sus alrededores, el año 2010. En la obra, uno de los actores señala que "el costo mayor del destierro, del exilio, (es el) sentido de pertenencia" (16). La imagen presentada en escena que sintetiza esta mirada corresponde a aquella en la que el actor, para explicar -a los otros integrantes del elenco- la sensación de desarraigo, siempre irreductible a los elementos reales que la constituyen, arranca una planta de un macetero y la arroja al suelo. Esta imagen permite que unos y otros accedan al 
P. Henríquez P., J. P. Amaya G., C. Díaz C., C. Contreras B., L. Flores. Dramaturgias de la memoria del teatro contemporáneo de Concepción

inconsciente de una visión de realidad que conecta al hombre con su entorno. Así como la planta arrancada pierde la única vía a través de la cual absorbe agua y nutrientes, el hombre “arrancado" pierde sus referentes y su entorno de sentimientos y pensamientos de arraigo y pertenencia.

La reconstitución de una microhistoria supone la puesta en funcionamiento de estrategias que permiten tomar lo particular como punto de partida y, en palabras de Levi, proceder a identificar su significado a la luz de su contexto específico (137). A lo mejor ahora está lloviendo incluye el siguiente epígrafe a modo de declaración metodológica: "Investigación teatral basada en el destierro" (1). La secuencia de la investigación (selección, disposición, análisis e interpretación de información) ha solido llevar al elenco, según palabras de la Directora, a las plazas de los pueblos a hablar con la gente, a las bibliotecas y hemerotecas locales y a revisar sus propias biografías, de modo de restablecer lo que Halbwachs identifica como la "intuición sensible", es decir, aquello que está en la base de todo recuerdo, el recuerdo de un estado de conciencia puramente individual (37), que los acerque a los acontecimientos gravitantes de un tiempo y lugar, pero también a las emociones y pensamientos más íntimos que se originan en los entornos y circunstancias sociales.

A partir de materiales diversos, incluyendo los propios testimonios, el elenco propuso una división de la obra en cuatro cuadros: Prólogo, Despojo (del pueblo mapuche), Exilio (en dictadura), Desplazamiento (Pobladores de sector Aurora de Chile) y Final, cada uno cristaliza en un montaje de fragmentos que, suspendiendo sistemáticamente la ilusión de realidad, pone ante los ojos de los espectadores formas de conciencia del pasado compartidas. El espectador está invitado a descubrir la red de relaciones que se esconde tras los fragmentos (Didi-Huberman 70), como a ser testigo de las formas a través de las cuales se muestra la crisis de la representación, una de las cuales es el metalenguaje teatral. Advierte Baboun que "metalenguajear es hacer referencia al propio lenguaje de una forma autorreferente, irónica. Ponerlo en crisis, enfrentarlo al escenario, cuestionarlo como un elemento dentro de una totalidad" (23). En A lo mejor ahora está lloviendo, el metalenguaje se aparta del registro de la ironía, con lo cual desaparece la distancia que ésta genera, para acercarse al "detalle autobiográfico" (Baboun 23), relacionado con la microhistoria local de una de las comunas más representativas de la región del Biobío, Coronel. 
Maira: Así recorríamos en bici, todo Coronel y la gente andaba como más alegre, nos saludaban, sonreían, como que era un pueblo lleno de colores, más alegre. Y ahora cuando voy a ver a mis tatas a Coronel, veo un pueblo gris, hediondo, contaminado, con el aire denso.

¿Quién tiene el derecho de llegar y poner una termoeléctrica ahí? ¿Quién tiene el derecho de contaminar a toda una ciudad? Y a sacar a esa gente que vivía ahí, sacarlas de su lugar, en donde han vivido toda la vida, para llegar y poner una termoeléctrica. A esa gente la sacan de su lugar, los destierran, ellos son desterrados... el destierro, ese es un tema para hacer una obra (Compañía La otra zapatilla, 2012).

Coronel, junto con Lota, "son ciudades que viven del carbón, o más bien de su recuerdo" (Vivallos y Brito 1). A mediados del siglo XX, la crisis y posterior cierre de las minas, puso en funcionamiento el controvertido Programa de Reconversión Laboral, con el objetivo de reinsertar laboralmente a los trabajadores y/o propiciar la puesta en marcha de alguna actividad productiva distinta. Es por todos conocido que este plan de reconversión fracasó, agudizando la crisis económica y social de miles de familias de la zona. Al descalabro económico se sumó la instalación de la Central termoeléctrica Bocamina (1), ubicada en el sector Lo Rojas de Coronel, foco de contaminación que "afecta los ecosistemas, la salud y la calidad de vida de las personas, vulnera sus derechos de acceso a recursos básicos para una vida digna” (Aedo y Larraín 5).

El detalle autobiográfico, propio de las llamadas "dramaturgias de lo real” (Sánchez 16), permite al elenco poner en común ciertos imaginarios silenciados, que dan cuenta de otras formas de destierro, muchas veces naturalizadas por la comunidad: la contaminación del aire a través de la emisión de gases tóxicos y la contaminación del agua y los suelos.

"A fines del año 2000, se constataba que en la zona de Coronel existían altos niveles de dióxido de azufre (SO2), afectando particularmente a las villas Yobilo I, Villa Alegre, Cerro Obligado, Estación Ferrocarriles y Cementerio. Esta contaminación se atribuye principalmente a las emisiones de la Central Termoeléctrica Bocamina.” (22)

El recurso del metalenguaje convive en esta obra con una construcción en fragmentos, es decir, con una construcción desde la discontinuidad de una sucesión de 
P. Henríquez P., J. P. Amaya G., C. Díaz C., C. Contreras B., L. Flores. Dramaturgias de la memoria del teatro contemporáneo de Concepción

situaciones que se "critican dialécticamente las unas a las otras" (Didi-Huberman) y que en la interrupción generan ciertos espacios vacíos que, como señala Stranger en relación a la dramaturgia contemporánea, facilitan "la aparición de textos, imágenes y personajes" (49).

Oscar... La araucaria tiene que ser grande, sus raíces deben meterse entremedio de su tierra y estar al lado de las otras araucarias. Entonces, ¿Quién tiene el derecho de decir "esta es mi tierra? ¿Quién puede adjudicarse la tierra de otro? ¿De quién es la tierra?

En la mesa los tres. Al ritmo del cajón peruano se muestra el paso del tiempo a través de una coreografía gestual. Daniela toca el cajón.

Oscar y Maira tocan cajones y delimitan el espacio de Daniela, dos veces. Daniela baila, cada vez en un espacio más reducido.

\section{Todos: DESPOJO}

\section{DESPOJO}

Los 3 actores discuten, hasta que se enojan y cada uno se va para un lado, pero regresan para interpretar un personaje

Oscar: Pablo Carbullanka.

Maira: Catalina Calfulen

Oscar: Mi abuelo le inculcó eso a sus hijas, que tenían que estudiar, entonces las mandó a un internado a la ciudad más cercana, que en ese entonces era Cañete.

Y ahí mi mamá me cuenta que sufrió mucho porque le mezquinaban las cosas" (Compañía La otra zapatilla, 2012)

A lo mejor ahora está lloviendo se caracteriza por disolver ese imperativo "de una acción que se desarrolla en el tiempo y en el espacio desde el principio hasta el final" (Viviescas 440), para dar paso a un montaje de fragmentos narrados por cada uno de los integrantes del elenco, a veces entre sí y en otras ocasiones, en una especie de monólogo que no entra en un diálogo interpersonal.

En el caso de la dramaturgia de la obra Víctor, un canto para alcanzar las estrellas, estrenada en Concepción en agosto de 2013, nos encontramos con formas de conciencia de un pasado políticamente complejo referido a la Dictadura Militar (1973-1989). Aquí, de igual modo a como ocurrió en A lo mejor ahora está lloviendo, la dramaturgia se construyó a partir de la investigación y de la recopilación testimonial directa e indirecta. El resultado fue la reescritura de la vida de Víctor Jara, ícono de la canción chilena, torturado y asesinado en 
el Estadio Nacional al inicio de la dictadura militar (1973), y personaje popular que dio sentido poético a las microhistorias locales y marginales del país de ese entonces. A través de la relectura de su figura, la Compañía logró con éxito recorrer y remontar el tiempo en búsqueda de ciertos recuerdos silenciados y olvidados como estrategia de instrumentación de la memoria.

La vida de Víctor Jara es hasta el día de hoy depósito de memoria cultural y colectiva que, al ser recreada escénicamente resulta en un ensamblaje de lenguajes y símbolos que dan sentido a varias generaciones de chilenos. La rememoración del pasado, tal como señala Todorov, es necesaria para afirmar la identidad de todo aquel que se reconozca en él, tanto los individuos como el colectivo (8).

Óscar Cifuentes, Director de Víctor, un canto para alcanzar las estrellas, explicó que esta obra fue el resultado de dos motivaciones. La primera, relacionada con la gran admiración que el elenco sentía y siente por la figura de Víctor Jara; y la segunda, relacionada con el interés de visibilizar, a través de la puesta en escena, el nexo que mantuvo Víctor Jara con el teatro, la danza y la música, convirtiéndolo en un artista integral que entendía el arte como un todo, y donde la expresión artística era una herramienta de transformación social.

El proceso de investigación para construir esta obra significó entre otras cosas, las siguientes etapas: recopilación de antecedentes, sistematización de relatos autobiográficos; y lectura, análisis e interpretación de los textos de sus canciones, como de su música. Lo interesante de este proceso es que la construcción escénica final hizo visible la investigación y las distintas voces y formas de enunciación. Por un lado, la historia de vida de Víctor: infancia, juventud, adultez, muerte; por otro, el contexto: su relación con el canto, el teatro y la política; y, por último, el testimonio de cada uno de los intérpretes que se materializó en relatos de vivencias relacionadas directa y/o indirectamente con el ícono Víctor bajo dos interrogantes principales: ¿Cómo aparece Víctor en mi vida? y ¿Qué sé de él? Estos testimonios, en el sentido de relatos por medio de los cuales alguien da a conocer algo que actúa como una experiencia (Agamben 9), constituyen la base para que el espectador entre en el siguiente juego de construcción: ese grupo de actores que está en escena reconstruye a partir de materiales y voces diversas la historia de Víctor, rompiendo de esta forma con la idea de que la obra sea sólo es una recreación histórica de su vida, incluso, que sea una 
P. Henríquez P., J. P. Amaya G., C. Díaz C., C. Contreras B., L. Flores. Dramaturgias de la memoria del teatro contemporáneo de Concepción

mímesis de su vida. Aquí, los actores entran y salen de la ficción a través de sus propios testimonios, lo que hace que la dramaturgia se vuelva más dinámica y compleja, tornándola sugerente y particular. Existen escenas en las que se recrea la infancia de Víctor Jara en el campo y en un entorno de precariedad, relato que se enlaza con el testimonio de una de las actrices que cuenta la historia de su hermano. Así mismo, existen otras en las que se recrea el encuentro entre Johan Turner y Víctor Jara en la universidad, relato introducido por otro de los actores que cuenta cómo conoció a Víctor en el Centro de danza Calaucán, a través de las coreografías que allí realizaban con la música del cantautor. De esta manera, en esta propuesta, el elenco en su conjunto, así como también cada uno de los espectadores, recuerda ese vínculo establecido con la figura del cantautor. De ahí que sea posible señalar que en esta obra se ponen de relieve las verdades subjetivas o como diría Richard Schechner, las cintas de conducta que en la performance (entendida como lo teatral) se restauran para generar las acciones, repercutir en el cuerpo y generar la composición escénica. Estas verdades subjetivas se proponen como base para la configuración de la memoria cultural y colectiva.

La dramaturgia que se construye en base a la investigación da cuenta de ese proceso, volviéndolo performativo. No existe aquí una historia lineal y secuencial, sino que aparecen en ella esos "fantasmas de la memoria" que menciona Marvin Carson y que son los que dan matices a la historia y los que significan estética y emocionalmente, conmueven por el sólo hecho de develar aquello que se ha olvidado, aquello que la historia oficial no cuenta, son esas historias particulares las que demuestran la permanencia del ícono musical, y al mismo tiempo su permanencia como un ser humano valiente, sensible y provocador.

\subsection{Compañía Teatro Uno}

La compañía Teatro Uno data del año 2011, fecha desde la que ha tenido una presencia sistemática en la escena teatral de la ciudad. Niño perro de Luis Barra Lira es la obra con la que inauguran sus actividades teatrales. Esta obra de ocho escenas está compuesta por sólo dos personajes, nombrados como "Niño Perro" y "Chica del Puerto". El personaje central es Niño Perro, un símil de los niños lobos en la Europa medieval, basada en 
el caso real de Miguel Luengo ${ }^{2}$, quien vive en el puerto de Talcahuano junto a sus perros, en abandono y drogadicción. Por otro lado, el personaje de la Chica del Puerto es un ente extraño, cuya función es interpelar al personaje principal, hacer que exponga su origen y ofrecerle una redención junto a ella; su conformación como personaje es inverosímil y con detalles externos al conflicto de la obra.

Las dos primeras escenas corresponden a la presentación de los personajes que a modo de monólogo exponen su presente y algunos hechos que los han llevado a ese estado. Desde la tercera escena, hay una interacción dialógica entre éstos, marcada por la tensión provocada por la Chica del Puerto al ser la única ciudadana que lo busca y se detiene a mirarlo, hablarle de su propuesta de llevarlo con ella aún a costa de la muerte de sus queridos perros.

Tanto los monólogos como los diálogos son poéticos y en ningún grado son reflejo de la marginalidad de los personajes, pues no se acercan al registro coloquial esperable en un teatro realista. Esta decisión por un lenguaje poético es válida en el teatro contemporáneo, sobre todo en el teatro postmoderno; ejemplo de ello es la dramaturgia de Luis Barrales, especialmente en HP (Hans Pozo), en que se mezcla la belleza poética con la crueldad de las imágenes:

Soy el perro guacho, vivo dentro de un gran espectáculo, soy la atracción, todos compran su entrada para verme, se pelean, se arrancan la piel a pedazos tratando de conseguir una entrada para verme, se pelean, se arrancan la piel a pedazos tratando de conseguir una entrada y poder asistir a mi derrota, aplaudir al perro, mear al perro, escupir al perro, hacerlo bailar, comprarle un helado y cerrarle un ojo. Para más no da. (Barra 4)

Pese a que en momentos el conflicto principal es desplazado por los problemas que la Chica del Puerto tiene con respecto a su familia, su ceguera inventada y su ánimo de venganza $^{3}$, es interesante la propuesta de contenido que hace la obra porque pone en escena aquello que la historiografía tradicional y oficial no considera, enfatizando en el nivel de la

\footnotetext{
${ }^{2}$ Miguel Luengo se hizo popularmente conocido a partir del año 2001, cuando Carabineros de Talcahuano lo presenta limpio y vestido con ropas de niño ante los medios de comunicación, interesados en cubrir la noticia del niño reincorporado a la vida social.

3 En una lectura dramatizada el 2015, en el marco de un proyecto de artes escénicas de la Corporación Artistas del Acero (Concepción), la obra prescindió de gran parte de los diálogos del personaje Chica del Puerto, para dar realce a las palabras de Niño Perro. Así, la Chica del Puerto cumple un rol interpelador y su ceguera inventada es el símbolo de su incapacidad de comprender las motivaciones y sentimientos de Niño Perro, que por extensión es también la ceguera de los habitantes del gran Concepción.
} 
P. Henríquez P., J. P. Amaya G., C. Díaz C., C. Contreras B., L. Flores. Dramaturgias de la memoria del teatro contemporáneo de Concepción

microhistoria y en la valorización del testimonio, ambos elementos importantes para la configuración identitaria de una ciudad puerto como Talcahuano.

Si bien el sujeto real que es asunto de la obra aún habita y deambula por el puerto junto a sus perros, pareciera ser que es un personaje invisibilizado por quienes habitan y transitan por la ciudad o aquellos que lo ven y le hablan de modo cruel. Su apodo de Niño Perro lo bautiza como uno más de los personajes típicos de una ciudad y con ello la obra realiza un trabajo creativo parecido al de Maha Vial en El paso del Chaucha Brujas, la Lala y otras historias de Valdivia (2010) al rescatar esos personajes e historias citadinas.

Esta dramaturgia se opone al olvido inexorable y busca restituir a una figura marginal de la ciudad. Ya sea por la conducta restaurada (Schechner 13) o el proceso restaurativo (Taylor 7), esta obra de teatro trabaja con la memoria reciente de la comunidad para evitar su olvido, pues pone en escena el mismo cuerpo y materiales físicos que pueblan el horizonte de expectativas de los espectadores. Sirva de ejemplo este fragmento del inicio de la obra: "Los perros regresan con la comida, pasa la gente, no quieren mirar, hacen como si los perros y el niño no existieran" (Barra 4). Por eso tiene mucho sentido el subtítulo de la obra: "Omisión de una vida perra", porque finalmente es visto como un sujeto sin derechos ciudadanos, un sin estado, un ser abyecto para la racionalidad moderna.

Así, el trabajo con la memoria en contra del olvido participa de la política que hace la literatura (Ranciere) y, doblemente el teatro, pues interviene en aquello que no queremos mirar y lo visibiliza reiterativamente, porque la figura del niño perro no se desvanece tan fácil por la ciudad. En la obra, el protagonista dice: "Resisto a lo mezquino, resisto al olvido" (Barra 2).

Los lectores y espectadores recepcionan la obra en virtud de su horizonte de expectativas (Jauss, 1978), es decir, a partir de los residuos de las experiencias anteriores semejantes. En particular, el receptor del gran Concepción, interpreta la obra desde su experiencia como testigo del niño sobreviviente gracias al calor de sus perros, lo ha visto en Talcahuano, lo ha visto en televisión cuando la morbosa programación apela a los márgenes como si fuera un bestiario medieval, ha escuchado de él como un mito urbano que se difunde oralmente. 
A lo largo de la obra, lectores y expectores no son interpelados directamente a tomar una actitud específica, salvo al final en la que hay una apelación al público, para que deje su cómodo rol de testigo y sea parte de su abandono materno:

Mi madre ¿se acordará de mí? ¿Mi madre pensará en mí?

Si alguien la ve le dice que me convertí en perro el mismo día que me olvidó, que me prendí fuego, solito, que ya no estoy. (Barra, 2011)

Pese a lo anterior, en su configuración, la obra no aspira a la representación épica, ni a la reflexión y movilización política. La escritura de Miguel Barra Lira y la puesta en escena de la compañía Teatro Uno se caracterizan por una poética más cercana al teatro de la crueldad de Artaud.

La búsqueda es hacia "una catarsis metafísica por medio de la crueldad” (Piedra 127), a partir de una escenificación que pone atención especial en gestos, sonidos y movimientos. Así, la puesta en escena presenta gritos de dolor, movimientos y golpes, junto con la presencia de la sangre y el cuerpo desnudo. Por momentos, la violencia de la escena, desplaza el rol enunciativo y poético del lenguaje, para representar la crueldad, no imitarla.

\section{6. $\quad$ Notas finales}

La producción teatral contemporánea de Concepción se instala en la tradición teatral de la ciudad y en sus formas de representar o presentar el mundo ante el lector espectador. Los antecedentes de esta tradición teatral, lo hemos señalado en textos anteriores, se encuentran en uno de los capítulos fundamentales de las historias del teatro chileno, en las historias del Teatro de la Universidad de Concepción, TUC, elenco que marcó a mediados del siglo XX el proceso de renovación del teatro chileno.

Hoy la producción teatral de la ciudad vive un momento de interés mayor para la historia del teatro chileno del siglo XXI: existe dramaturgia, investigación, creación escénica y espectadores interesados en vivir la experiencia de una de las artes que con mayor plenitud fortalece los tejidos sociales, en tanto devuelve a la comunidad, lecturas de realidad intensificadas por los lenguajes de lo simbólico y lo poético. 
P. Henríquez P., J. P. Amaya G., C. Díaz C., C. Contreras B., L. Flores. Dramaturgias de la memoria del teatro contemporáneo de Concepción

El teatro actual de Concepción expone ante las miradas propias y ajenas un registro de lo que en el arte de vernos a nosotros mismos se incuba en la ciudad. Se trata de un teatro que toma posición para hacer visible lo que era invisible y para hace audibles a aquellos que no eran oídos; que explora en las formas de "metalenguajear" la escena teatral local y en la construcción dramática en fragmentos; que restaura el valor del testimonio del que da a conocer una experiencia vivida y del sobreviviente en tanto seudotestigo que habla por delegación; y entre otras cosas, que sintetiza en tanto registro, la experiencia irremplazable a través de la cual se trasladan las cosas vistas a las cosas dichas (Ricoeur 24).

\section{Bibliografía}

Aedo, Paz, Larraín, Sara. Impactos ambientales en Chile. Desafíos para la Sustentabilidad. Santiago: LOM Ediciones, 2004. http://www.archivochile.com/Chile_actual/patag_ sin_repre/03/chact_hidroay 3\%2000014.pdf

Baboun, Isabel. "Guillermo Calderón: Tres motivos para una poética casi trágica". Revista Apuntes, 131 (2009): 20-28. Impreso.

Barthes, Roland. El susurro del lenguaje. Barcelona: Editorial Paidós, 1978. Impreso.

Barra, Miguel. Niño Perro. (Texto sin publicar). 2011.

Carlson, Marvin. El teatro como máquina de la memoria. Los fantasmas de la escena. Argentina: Ediciones Artes del Sur, 2009. Impreso.

Compañía La otra zapatilla. A lo mejor ahora está lloviendo. 2012. (Texto sin publicar).

Contreras, Marta, Henríquez, Patricia, Albornoz, Adolfo. Historias del teatro de la Universidad de Concepción. Universidad de Concepción, 2003. Impreso.

Cornago, Óscar. Pensar la teatralidad. Miguel Romero Esteo y las estéticas de la Modernidad. España: Editorial Fundamentos, 2003. Impreso.

Didi-Huberman, Georges. Cuando las imágenes toman posición. España: A.Machado Libros, 2008. Impreso.

Dubatti, Jorge. Cartografía teatral: introducción al teatro comparado. Argentina: Atuel, 2008. Impreso.

García Barrientos, José Luis. "Teatro y narratividad". Arbor CLXXVII. http://arbor.revistas.csic.es/index.php/arbor/article/view/592/594

Halbwachs, M. (2004), La memoria colectiva. Zaragoza: Prensas Universitarias de Zaragoza. http://www.slideshare.net/Gatojazzy/maurice-halbwachs-la-memoria-colectiva.

Jauss, Hans-Robert. Pour une esthétique de la recepción. Francia: Gallimard, 1978. Impreso.

Levi, Giovanni. "Sobre Microhistoria". Formas de hacer historia. Edición de Peter Burke. Madrid: $\quad$ Alianza, $\quad 1993 . \quad$ http://www.e-historia.cl/cursosupa/12-1 invhistoriografica/lecturas/01\%20Formas\%20de\%20Hacer\%20Historia $\% 20 \% 20 \mathrm{Burk}$ e.pdf

Mansilla, Sergio.“Literatura e identidad cultural”. Estudios Filológicos, 41(2006):131-143. http://www.scielo.cl/scielo.php?pid=S0071-17132006000100010\&script=sci_arttext

Matamala, Roberto. Teatro de Los Ríos. Antología crítica de la dramaturgia valdiviana contemporánea. Valdivia: Ediciones Kultrún, 2010. Impreso. 
Nietzsche, Frederich. La Genealogía de la Moral. Un escrito polémico.1987. http://www.biblioteca.org.ar/libros/211756.pdf

Pavis, Patrice. Diccionario del teatro. Dramaturgia, estética, semiología. Barcelona: Editorial Paidós, 1998. Impreso.

Ranciere, Jacques. El lector emancipado. Buenos Aires: Manantial, 2011. Impreso.

--------. Política de la literatura. Buenos Aires: Libros del Zorzal, 2011. Impreso.

Ricoeur, Paul. La lectura del tiempo pasado: memoria y olvido. España: Editorial Arrecife, 1999. Impreso.

--------. La memoria, la historia, el olvido. México: Fondo de Cultura Económica, 2004. Impreso.

Rodríguez, Raúl. "Literatura y poder: Sobre la potencia del testimonio en América Latina". 2010. http://www.scielo.cl/scielo.php?pid=S0718-46220100007\&script=sci_arttext

Sánchez, Antonio José. Prácticas de lo real en la escena contemporánea. Madrid: Visor Libros, 2007. Impreso.

Schechner, Richard. Performance. Teoría y prácticas interculturales. Buenos Aires: Ed. Libros del Rojas, 2003. Impreso.

Spregelburd, Rafael. "El robo del http://es.scribd.com/doc/60561506/SPREGELBURD-Rafael-El-Robo-Del-Siglo

Steiner, Rudolf. Lecciones de los maestros. México: Fondo de Cultura Económica, 2004. Impreso.

Stranger, Inés. Cuaderno de Dramaturgia. Teoría, Técnica y Ejercicios. Santiago: Pontificia Universidad Católica de Chile, 2011. Impreso.

Taylor, Diana. Hacia una definición de performance. 2013. http://132.248.35.1/cultura/ponencias/PONPERFORMANCE/Taylor.html

Todorov, Tzvetan. Los dilemas de la memoria. Cátedra Latinoamericana Julio Cortázar. Conferencia

Magistral.

2000.

http://www.jcortazar.udg.mx/sites/default/files/TODOROV.pdf

Vivallos, Carlos y Brito, Alejandra. "Inmigración y sectores populares en las minas de carbón de Lota y Coronel (Chile 1850-1900)". Atenea, 501(2010):73-94. http://www.scielo.cl/scielo.php?pid=S07104622010000100005\&script=sci_artt ext

Viviescas, Víctor. "La crisis de la representación y de la forma dramática". Centro de Investigación $\quad y \quad$ desarrollo científico. 2005. http://cidc.udistrital.edu.co/investigaciones/documentos/revistacientifica/rev7/Unidad $\% 2021 \% 20$ pags\%20437-465.pdf 